\title{
Morphological changes at the interface of the nickel-yttria stabilized zirconia point electrode
}

\author{
Aaberg, Rolf Jarle; Tunold, Reidar; Mogensen, Mogens Bjerg; Berg, Rolf W.; Ødegaard, Rolf
}

Published in:

Journal of The Electrochemical Society

Link to article, DOI:

$10.1149 / 1.1838628$

Publication date:

1998

Document Version

Publisher's PDF, also known as Version of record

Link back to DTU Orbit

Citation (APA):

Aaberg, R. J., Tunold, R., Mogensen, M. B., Berg, R. W., \& Ødegaard, R. (1998). Morphological changes at the interface of the nickel-yttria stabilized zirconia point electrode. Journal of The Electrochemical Society, 145(7), 2244-2252. https://doi.org/10.1149/1.1838628

\section{General rights}

Copyright and moral rights for the publications made accessible in the public portal are retained by the authors and/or other copyright owners and it is a condition of accessing publications that users recognise and abide by the legal requirements associated with these rights.

- Users may download and print one copy of any publication from the public portal for the purpose of private study or research.

- You may not further distribute the material or use it for any profit-making activity or commercial gain

- You may freely distribute the URL identifying the publication in the public portal 


\title{
Morphological Changes at the Interface of the Nickel-Yttria Stabilized Zirconia Point Electrode
}

\author{
Rolf Jarle Aaberg, ${ }^{a}$ Reidar Tunold, ,,a Mogens Mogensen,",b Rolf W. Berg, ${ }^{c}$ and Rolf Ødegård*,a,d \\ ${ }^{a}$ Institutt for Teknisk Elektrokjemi, Noregs Teknisk-Naturvitskaplege Universitet, $N$-7034 Trondheim, Norway \\ ${ }^{b}$ Afdelingen for Materialeforskning, Forskningscenter Risø, DK-4000 Roskilde, Denmark \\ ${ }^{\text {'} I n s t i t u t ~ f o r ~ K e m i, ~ D a n m a r k s ~ T e k n i s k e ~ U n i v e r s i t e t, ~ D K-2800 ~ L y n g b y, ~ D e n m a r k ~}$ \\ ${ }^{d}$ Statoil Forskingsenter, N-7005 Trondheim, Norway
}

\section{ABSTRACT}

The $\mathrm{H}_{2}-\mathrm{H}_{2} \mathrm{O}$, Ni/YSZ point electrode has been investigated using long-term potential step measurements and impedance spectroscopy at $1273 \mathrm{~K}$. Morphological and structural changes at the electrode interface were evaluated by electron microscopy, energy dispersive X-ray analysis, and Raman spectroscopy ex situ. The anodic current was found to induce a self-catalytic effect on the electrode, and the anodic "steady state" current increased to more than twice the initial value with a time constant of about $40 \mathrm{~h}$. In contrast, cathodic polarization reduced the performance of the electrode, and the cathodic current decreased significantly with a time constant of about $20 \mathrm{~h}$. Redistribution of material in the reaction zone is suggested to control most of the changes in electrode activity. At anodic overpotentials it was observed that Ni was transported to the electrolyte surface, forming a "necklace" of Ni particles around the electrode/electrolyte contact. This is believed to increase the three-phase boundary (TPB) length and account for the higher activity of the electrode. At cathodic overpotentials the transfer of $\mathrm{Ni}$ to the YSZ was found to be restricted, and it is proposed that agglomeration of dispersed metal particles reduced the TPB length, and accordingly the cathodic current. In addition to the morphological modifications, the catalytic properties of the surfaces were significantly altered as the electrode was polarized. Transformation from cubic to tetragonal YSZ, due to segregation of the material, was observed on the surface of the electrolyte when the sample was kept at working conditions for long periods of time (135 days). The passage of current was not found to generate any permanent phase transformation in the YSZ.

\section{Introduction}

High temperature gas, metal/yttria stabilized zirconia (YSZ) electrodes are used in technical applications such as solid oxide fuel cell anodes and $p_{\mathrm{O}_{2}}$ sensors. Despite the many investigations over the last decades, there is still a lack of detailed knowledge about the processes on such electrodes. ${ }^{1}$ It is understood that the catalytic activity of $\mathrm{Pt} / \mathrm{YSZ}$ electrodes is enhanced by high anodic currents. According to Pizzini et $\mathrm{al}^{2}{ }^{2}$ the current treatment generates new catalytic sites which account for the higher activity. Schouler and Kleitz ${ }^{3}$ suggested that the electrode reaction is promoted by the onset of electronic conductivity in the electrolyte subsurface upon passage of current. This is believed to result in an expansion of the reaction zone and give rise to the low-frequency inductive loop observed in the impedance spectra. Recently, Jacobsen et al. ${ }^{4,5}$ observed that transport of electrolyte material was induced by the current at the $\mathrm{O}_{2}, \mathrm{Pt} / \mathrm{YSZ}$ point electrodes. These morphological changes are suggested to give rise to variations in the extension of the reaction zone and, consequently, account for the inductive relaxation times in the order of 2.5 to $26 \mathrm{~h}$.

Understanding the catalytic and morphological properties of metal/YSZ electrodes is mandatory before the electrochemical processes can be evaluated in detail. The present work is treating these phenomena with respect to the $\mathrm{H}_{2}-\mathrm{H}_{2} \mathrm{O}$, Ni/YSZ point electrode, which is a geometrically simplified model of the Ni/YSZ cermet anode used in solid oxide fuel cells.

\section{Experimental}

The working electrodes were prepared from nickel wires, either $1 \mathrm{~mm}(99.8 \%)$ or $0.5 \mathrm{~mm}$ in diameter $(99.9 \%)$. The wire was bent into a U shape and held in place with an alumina support. Polycrystalline YSZ electrolytes containing $8 \mathrm{~mol} \% \mathrm{Y}_{2} \mathrm{O}_{3}$ were manufactured as described by Mogensen et al. ${ }^{6}$ They were produced from Tosoh TZ8Y powder, isostatically pressed at about $400 \mathrm{MPa}$ for $30 \mathrm{~s}$ and sintered at $1600^{\circ} \mathrm{C}$ for $2 \mathrm{~h}$ in air. The surface of the electrolyte was then polished with $1 \mu \mathrm{m}$ diamond paste before the cell was mounted in a three-electrode four-wire arrangement as shown in Fig. 1. The electrode was pressed against the electrolyte with a weight of about $460 \mathrm{~g}$, corresponding to a

* Electrochemical Society Active Member. mechanical pressure in the order of $10 \mathrm{MPa}$. The electrode/electrolyte contact area was typically about $0.5 \mathrm{~mm}^{2}$, estimated both from the Newman formula ${ }^{7}$ and from scanning electron micrographs of the electrolyte surface.

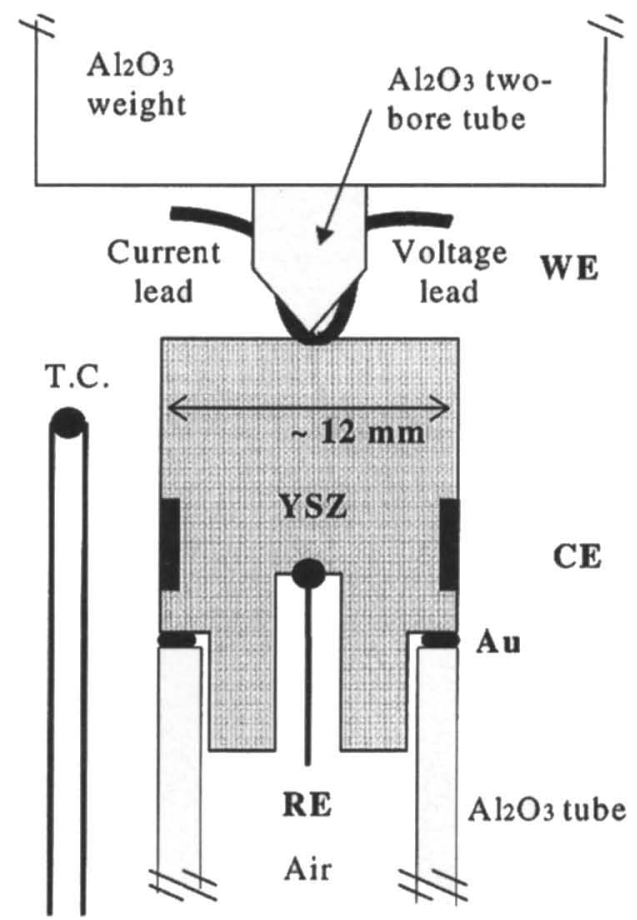

Fig. 1. Cross section of the cell configuration. The working electrode (WE) was made by bending a Ni wire into $U$ shape and mounting it in a two-bore $\mathrm{Al}_{2} \mathrm{O}_{3}$ tube. $\mathrm{An} \mathrm{Al}_{2} \mathrm{O}_{3}$ weight pressed the working electrode against the electrolyte and held it in position. The counter electrode (CE) was a stripe of Pt paste painted around the periphery of the cylindrical YSZ pellet. The electrolyte was mounted on top of an $\mathrm{Al}_{2} \mathrm{O}_{3}$ tube and sealed by a gold O-ring (Au). A $P$ t point exposed to synthetic air was used as the reference electrode (RE). The whole assembly was placed inside a high-purity $\mathrm{Al}_{2} \mathrm{O}_{3}$ tube in the furnace. The temperature was controlled by a thermocouple (T.C.) next to the working electrode. Further details are in the text. 
Six electrodes were investigated in various $\mathrm{H}_{2}-\mathrm{H}_{2} \mathrm{O}$ mixtures diluted with $\mathrm{N}_{2}$ to a total pressure of $1 \mathrm{~atm}$. The dry $\mathrm{H}_{2}-\mathrm{N}_{2}$ mixtures were bubbled through a temperature-controlled bottle of distilled water. In this way up to $50 \% \mathrm{H}_{2} \mathrm{O}_{(\mathrm{g})}$ was supplied in the gas flow to the furnace. The gas pipe between the bubbler and the furnace was heated at least $30 \mathrm{~K}$ above the actual dew point to avoid condensation of vapor. The partial pressure of $\mathrm{H}_{2} \mathrm{O}_{(\mathrm{g})}$ was verified both by measuring the open-circuit potential, typically within $\pm 2 \mathrm{mV}$ from the theoretical potential, and by measuring the amount of water collected by a condensation trap in the exhaust gas. The gas flow through the working electrode compartment was equal to $180 \mathrm{~mL} / \mathrm{min}$ at room temperature. The temperature at the electrode was $1273 \mathrm{~K}$. Each electrode assembly was operated for periods varying from 5 to 135 days. Long-term potential step measurements and impedance spectroscopy (Solartron 1286/Solartron 1255) were used to characterize the electrodes at potentials from -750 to $-1250 \mathrm{mV}$ vs. the air, Pt/YSZ electrode. The impedance spectra were recorded in the $100 \mathrm{kHz}$ to $5 \mathrm{mHz}$ cyclic frequency range with an amplitude of $20 \mathrm{mV}$.

After cooling and disassembling the cell, the working electrode and the electrolyte were investigated by low-vacuum scanning electron microscopy (LVSEM) (JEOL JSM 5310) and environmental scanning electron microscopy (ESEM) (Electroscan 2020) with energy dispersive X-ray analysis (EDX) (Link Isis). The crystallographic phases of the YSZ at, and near, the electrode contact point were studied by Raman spectroscopy through a microscope (Dilor $\mathrm{XY} 800$ with a modified Olympus microscope). The radiation source was a $514.5 \mathrm{~nm} \mathrm{Ar}^{+}$laser supplying a power equivalent to about $75 \mathrm{~mW}$ at the sample. The spectroscope was calibrated vs. the $\mathrm{Ar}^{+}$-plasma spectrum while the spectral slit width was $4.4 \mathrm{~cm}^{-1}$. The magnification was 50 or 100 times, corresponding to a lateral resolution of approximately 70 to $35 \mu \mathrm{m}$. Some of the YSZ samples were analyzed by X-ray diffraction (Philips with a modified PW1050 gonimeter) to verify the crystallographic phases of the bulk electrolyte. The instument was using $\mathrm{Cu} \mathrm{K} \alpha$ radiation with the wavelength $\lambda=1.54059 \AA$.

\section{Results}

After heating to the working temperature, the $\mathrm{Ni}$ wire electrodes deformed plastically under the applied mechanical pressure, and an intimate contact with the electrolyte was achieved. By impedance spectroscopy one could observe how the electrolyte resistance, $R_{\mathrm{s}}$, and the polarization resistance developed during the mechanical relaxation of the nickel. The potential step measurements were not initiated before 10 to $20 \mathrm{~h}$ after the start of the experiments, well after the formation of a geometrical stable contact between the $\mathrm{Ni}$ wire and the electrolyte. The effect of mechanical deformation can therefore be ignored in the experiments described below. Since the electrode area is not well defined and a qualitative description was the main object of these investigations, the current and the impedance measurements are reported in absolute quantities instead of being related to the specific electrode area The applied potential was kept constant during the potential-step measurements, i.e., not corrected for the varying ohmic $\left(I R_{5}\right)$ voltage drop as the current changes. However the lack of $I R_{\mathrm{s}}$ compensation does not alter the general trends reported and discussed below. Unless otherwise noted, the potentials reported here are corrected numerically after the measurement.

Long-term potential-step measurements.-A typical anodic potential-step measurement is presented in Fig. 2 Although the time constants of the initial current transient could not be resolved, the current, $I$ increased inductively from zero to about $140 \mu \mathrm{A}$ within $5 \mathrm{~s}$. A small decrease followed during the next $10 \mathrm{~h}$, before a pronounced increase in the electrode activity was observed, resulting in a steady-state current more than twice the initial level. This slow transient is fitted to the equation

$$
I(t)=I^{\infty}-\left(I^{\infty}-I^{0}\right) \exp (-t / \tau)
$$

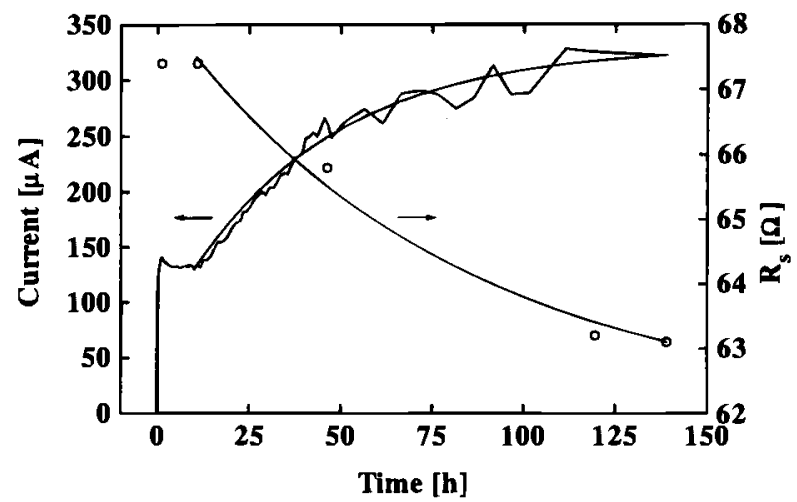

Fig. 2. Anodic current and electrolyte resistance in $50 \% \mathrm{H}_{2}$ and $5 \% \mathrm{H}_{2} \mathrm{O}$ as function of time at $-750 \mathrm{mV}$ vs. $\mathrm{Pt} /$ air (non- $/ R_{s}$-corrected). The $\mathbb{R}_{s}$-corrected overpotential at steady state, $\eta_{\mathrm{ss}} \approx$ $230 \mathrm{mV}$. The time constant for the slow increase in the current is estimated to be $40 \mathrm{~h}$, whereas the change in the electrolyte resistance has a time constant of $\sim 80 \mathrm{~h}$. Prior to the anodic potential step, the electrode had been polarized to various cathodic overpotentials for $320 \mathrm{~h}$.

where $I$ is expressed as a function of time t, time constant $\tau$, steady-state current $I^{x}$, and initial current $I^{0}$. From the fitting result, $\tau$ is estimated to be $40 \mathrm{~h}$ for the current increase in Fig. 2. Figure 2 also shows how $R_{\mathrm{s}}$ decreased over the same period. The measurements indicated that $R_{\mathrm{s}}$ decreased somewhat more slowly than $I$ increased. A rough estimate, based on a fit to an equation of the same form as Eq. 1, suggests $\tau \approx 80 \mathrm{~h}$.

A cathodic polarization-step measurement was performed on the same electrode sample; it is presented in Fig. 3. The electrode had been resting at open-circuit voltage (OCV) for $6 \mathrm{~h}$ after a series of various anodic polarization experiments for a total period of $307 \mathrm{~h}$. The cathodic current increased over the first hour in a pseudo-inductive manner and reached a maximum before the electrode performance began to deteriorate. $I$ decreased about $65 \%$ before steady state was reached with $\tau \approx 20 \mathrm{~h} . R_{\mathrm{s}}$ increased during the cathodic polarization and returned approximately to the value observed prior to the preceding anodic polarization. The estimated $\tau$ for this increase was about $35 \mathrm{~h}$. In another experiment the electrode was left at OCV for $70 \mathrm{~h}$ after completing an anodic potential step. During this period $R_{\mathrm{s}}$ increased by $4 \%$. When a cathodic potential step was applied to the electrode, $R_{\mathrm{s}}$ increased further, although ten times more slowly than in Fig. 3 , equivalent to $\tau \approx 350 \mathrm{~h}$.

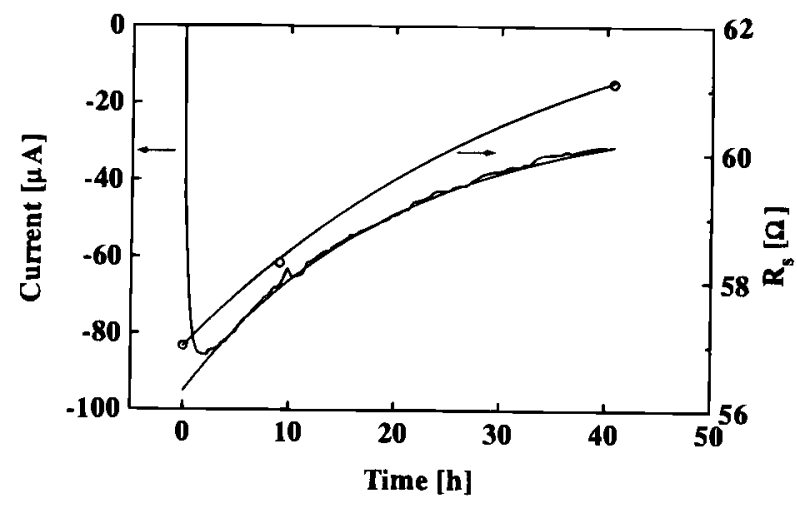

Fig. 3. Cathodic current and electrolyte resistance in $50 \% \mathrm{H}_{2}$ and $5 \% \mathrm{H}_{2} \mathrm{O}$ as a function of time at $-1150 \mathrm{mV}$ vs. Pt/air (non- $I R_{\mathrm{s}}$-corrected). The $\mathbb{R}_{\mathrm{s}}$-corrected $\eta_{\mathrm{ss}} \approx-147 \mathrm{mV}$. The time constant for the slow decrease in current is estimated to $20 \mathrm{~h}$, whereas the change in electrolyte resistance had a time constant of $35 \mathrm{~h}$. Prior to this experiment the electrode had been polarized continuously to various anodic overpotentials for a period of $307 \mathrm{~h}$. The electrode was allowed to rest at open circuit for $6 \mathrm{~h}$ before the potential step measurement started. 


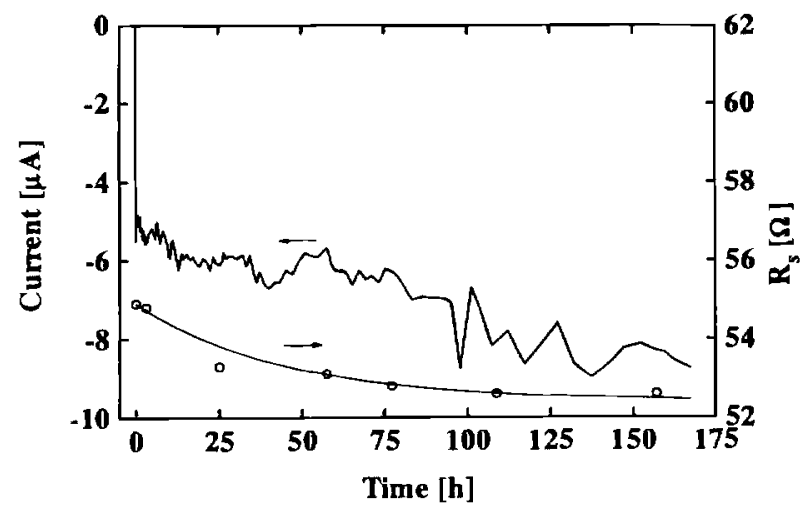

Fig. 4. Cathodic current and electrolyte resistance in $30 \% \mathrm{H}_{2}$ and $10 \% \mathrm{H}_{2} \mathrm{O}$ as a function of time at $-1086 \mathrm{mV}$ vs. $\mathrm{Pt} /$ air (non- $/ R_{5}$ corrected). The $\left(R_{\text {s }}\right.$-corrected $\eta_{\mathrm{ss}} \approx-149 \mathrm{mV}$. The time constant for the slow increase in current is estimated to be $20 \mathrm{~h}$, whereas the change in electrolyte resistance had a time constant of $35 \mathrm{~h}$. After heating to the operating temperature, the cell had been resting at OCV for 2 days before the cathodic step was applied.

The variations in $I$ followed approximately the same time constants as in Fig. 3, but the relative current decrease was only $17 \%$, significantly less than in the first case, where the electrode was not allowed to rest as long at open circuit.

By alternating the polarization of the electrode between anodic and cathodic potentials, we found that the catalytic activity of the electrode and the changes in $R_{s}$ could be reversed. However, the activity of the electrodes was hardly reproducible in the sense that the same steady-state current could be measured at the same potential in consecutive cycles. If the potential was reversed to its former level, after a short period (a few hours) at a lower overpotential, the steady-state current was obtained faster, yet not necessarily at the same level as previously. The long- term electrode performance and the potential-step transients were also depending on the polarization history of the electrode over the preceding days. Keeping the electrode polarized to high anodic overpotentials generated lower OCV polarization resistance than polarization to cathodic or moderate anodic potentials.

The electrode had been polarized to anodic and cathodic overpotentials several times before the measurement presented in Fig. 3 was performed. Two electrodes were polarized to cathodic potentials without any preceding anodic polarization to distinguish the effects of anodic and cathodic polarization. The result in Fig. 4, for one of the electrodes, shows an activation rather than deactivation and also that $R_{\mathrm{s}}$ was decreasing. Only minor changes in the electrode activity and $R_{\mathrm{s}}$ were observed for the other electrode during the initial cathodic polarization. This is in contrast to the observations on electrodes that had been polarized to anodic potentials prior to the cathodic step.

Impedance spectroscopy.-At open-circuit potential, the impedance spectra resembled a depressed semicircle in the Nyquist diagram, as shown in Fig. 5a. When the electrode was polarized to moderate anodic or cathodic overpotentials a low-frequency inductive loop developed, as observed in Fig. 5b and d. The inductive loops were also observed during the long-term pseudo-capacative relaxation at cathodic overpotentials, as when $I$ decreased at constant polarization in Fig. 3. Figure $5 \mathrm{c}$ shows that at higher anodic overpotentials the low-frequency tail is inflected back into the capacative quadrant of the Nyquist diagram. The shape of the spectra changed slowly to their new steadystate appearance. The time required for this transformation was the same as the time necessary to reach $I^{\infty} .^{8}$

Because the minimum cyclic frequency in the present impedance spectra was $5 \mathrm{mHz}$, the maximum time constant that could be measured was in the order of 10 to $100 \mathrm{~s}$. A simple fit of the low-frequency arc to an RQ-parallel circuit ${ }^{9}$ rendered time constants in the range from 5 to
Fig. 5. Impedance spectra at (a) $-980 \mathrm{mV}$ vs. air in $21 \%$ $\mathrm{H}_{2} / 3 \% \mathrm{H}_{2} \mathrm{O}$ (open circuit) (b) $755 \mathrm{mV}$ vs. air in $50 \% \mathrm{H}_{2} / 50 \%$ $\mathrm{H}_{2} \mathrm{O}\left(\eta_{\mathrm{ss}} \approx 121 \mathrm{mV}\right),(\mathrm{c})$ $-770 \mathrm{mV}$ vs. air in $21 \% \mathrm{H}_{2} / 3 \%$ $\mathrm{H}_{2} \mathrm{O}\left(\eta_{\mathrm{ss}} \approx 213 \mathrm{mV}\right)$, and (d) $-1149 \mathrm{mV}$ vs. air in $50 \%$ $\mathrm{H}_{2} / 5 \% \mathrm{H}_{2} \mathrm{O}\left(\eta_{\mathrm{ss}} \approx-147 \mathrm{mV}\right)$ The potential values are $\mathbb{R} R_{5}$-corrected.
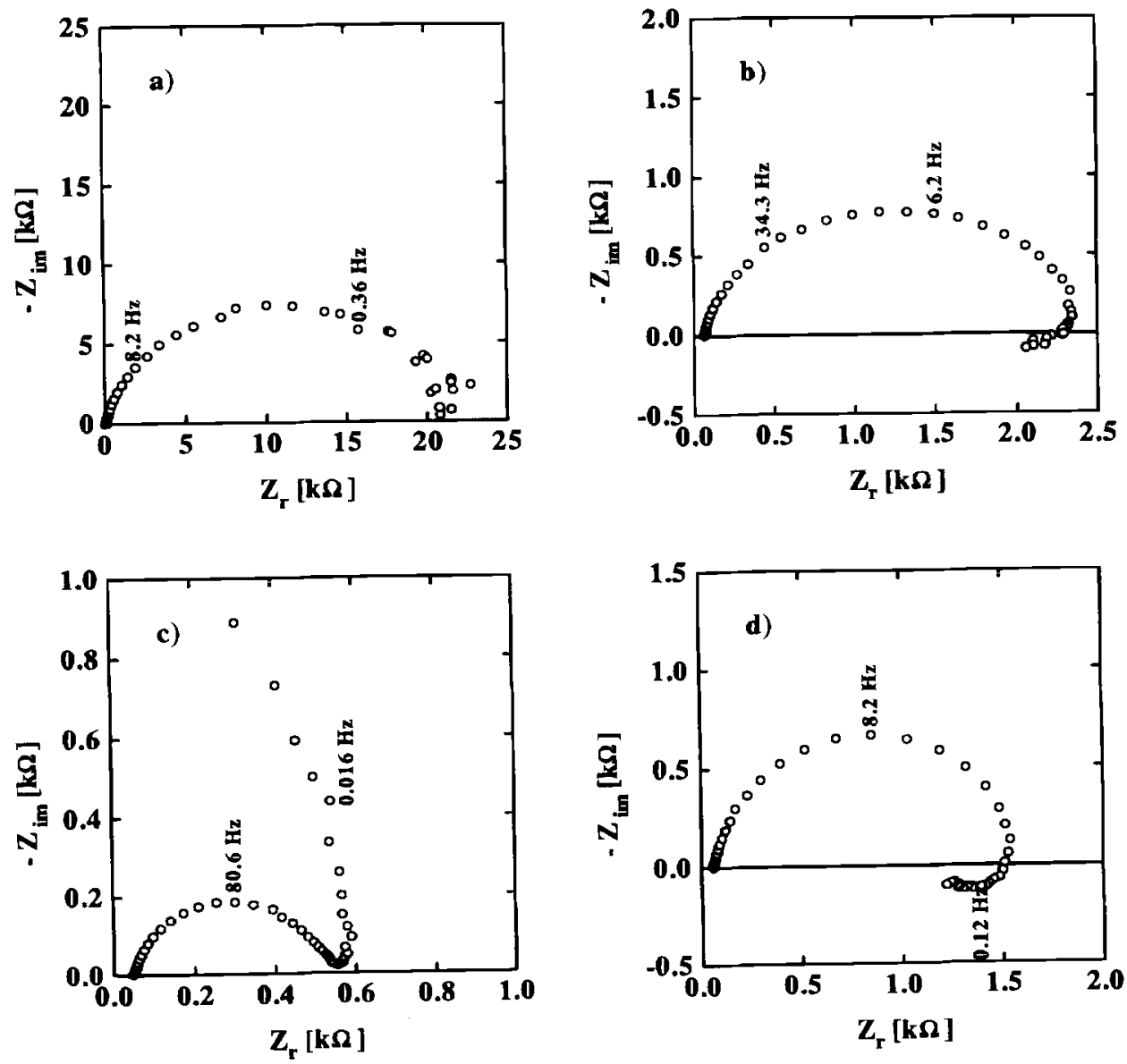
$80 \mathrm{~s}$ when using the relationship for "equivalent capacity" given by Jacobsen et al., ${ }^{4} R$ and $Q$ denoting ohmic resistance and constant-phase element, respectively. The slowest time constants of the impedance spectra are thus orders of magnitude less than the time constants observed in the long-term potential-step measurements.

Micrograph studies and EDX analysis.-The interface between YSZ and $\mathrm{Ni}$ was investigated ex situ after the samples had been cooled and dismounted. When examining the electrolyte surface, three characteristic areas could be distinguished after the electrochemical treatment. In Fig. 6, these have been classified as, A, the free electrolyte surface, $\mathrm{B}$, the border zone along the $\mathrm{Ni} / \mathrm{YSZ}$ contact area, and, $\mathrm{C}$, the actual contact area. By EDX analysis the particles at the periphery of the contact area were identified as metallic Ni. The marks and imprints that are visible on the YSZ surface between the metal grains were probably left by $\mathrm{Ni}$ particles which broke loose during handling of the sample. At greater magnification, as in Fig. 7, the crystal planes of the Ni particles can be seen, suggesting that the particles consist of only a few crystallites. Several smaller particles were discovered next to the Ni grains in Fig. 7. These probably also consist of $\mathrm{Ni}$, as no other impurity element was detected in any significant amount in this area.

$\mathrm{Ni}$ particles forming a necklace around the contact area were only found on two of the samples (Fig. 6 and 7). One of these had been polarized for 6 days and only at anodic potentials, while the other had been operated at both anodic and cathodic potentials over a period of 135 days. There was no significant difference in the amount of $\mathrm{Ni}$ in the border area although one of the electrodes had been in operation about 25 times longer than the other. In comparison, the two samples that were polarized only to cathodic potentials did not reveal any distributed metallic nickel around the periphery of the Ni/YSZ contact area, suggesting that the formation of $\mathrm{Ni}$ particles at the YSZ is promoted only at anodic potentials. No cavities could be found on the $\mathrm{Ni}$ wire adjacent to the contact area on any of the samples, as illustrated for example in Fig. 8, showing that the $\mathrm{Ni}$ grains observed in the border area cannot simply have scaled off from the wire.

For two out of the six samples, the electrode adhered so strongly to the electrolyte that pieces of YSZ were ripped out of the electrolyte when the cell was dismounted, as shown in Fig. 8. The bonding may have occurred due to the high mechanical pressure between the electrode and the electrolyte. ${ }^{10}$ The interfaces of these samples could not easily be studied by scanning electron micrographs, and it was impossible to establish whether any Ni particles had been present on the periphery of the contact area for these samples.

Figure 9 shows a section of the central contact area for a cell that had been operated at various anodic potentials for about six days. The grain boundaries are significantly etched; in addition, several grains are detached from the electrolyte by intergranular fracture. Similar etching and weakening of grain boundaries were found on several of the samples, but most clearly on the samples that had been polarized only to anodic potentials. On the samples that were polarized only to cathodic poteritials, one could hardly distinguish the grain boundaries at all. The surface of the electrodes had imprints of grain boundaries and scratches on the electrolyte surface, verifying that an intimate contact prevailed between $\mathrm{Ni}$ and YSZ.

Elemental analysis showed that some amount of $\mathrm{Ni}$ could be found on the contact area of the YSZ surface and was slightly enriched in the grain boundaries. An accumulation of the impurity elements $\mathrm{Mn}, \mathrm{Si}, \mathrm{O}$, and $\mathrm{Ti}$ was observed in the dark areas between $\mathrm{B}$ and $\mathrm{C}$ in Fig. 6 . The existence of $\mathrm{Mn}$ associated with excess oxygen was observed on several of the samples. Most of the contamination was usually found in the actual Ni/YSZ interface.

Raman spectroscopy and X-ray diffraction analysis.The spectrum in Fig. 10 was recorded at marker $A$ in Fig. 8. According to Kjerulf-Jensen et al., ${ }^{11}$ a broad asymmetric peak between 600 and $630 \mathrm{~cm}^{-1}$ is characteristic for

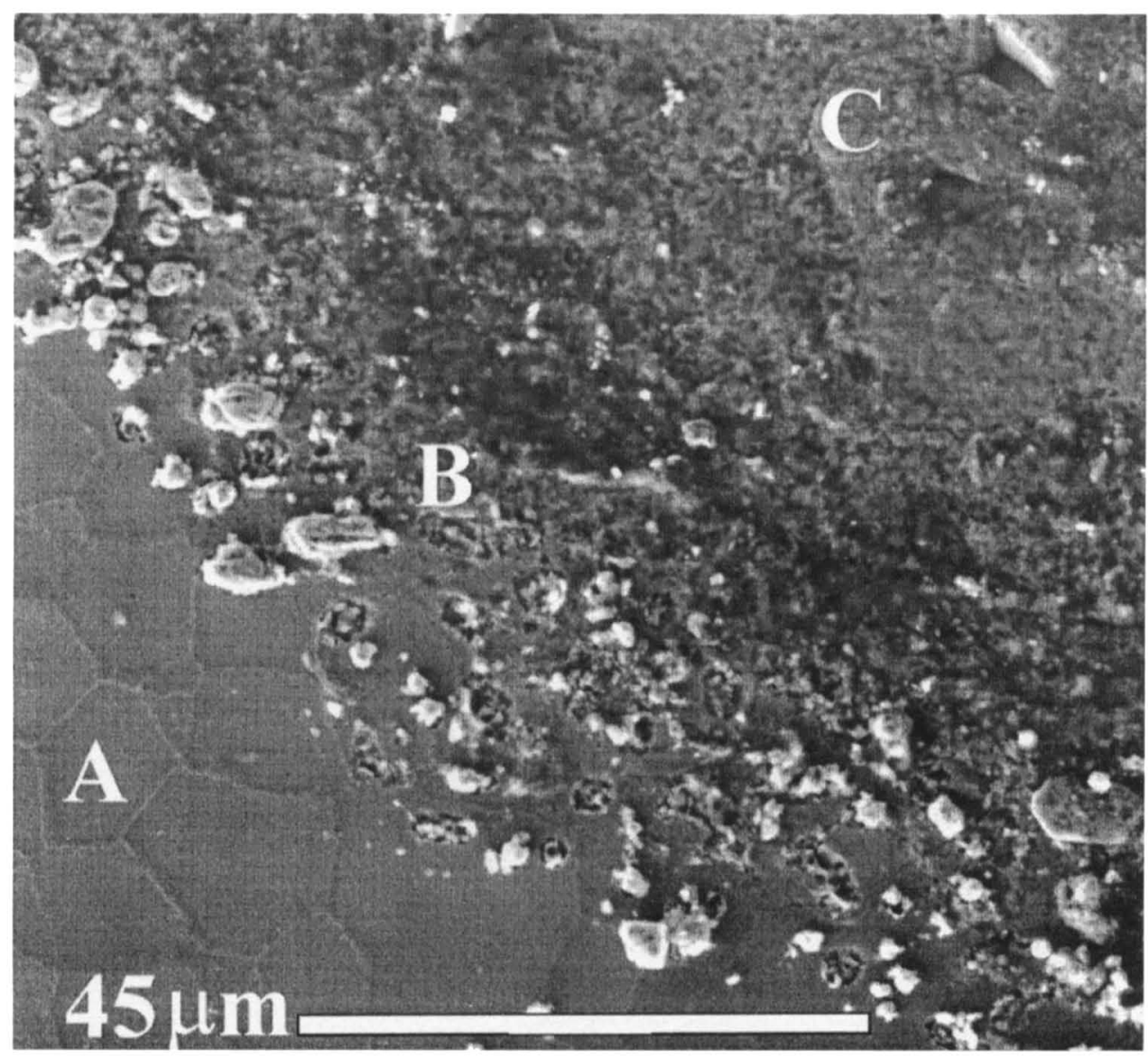

Fig. 6. ESEM micrograph of the YSZ surface at the periphery of the contact area. Three regions can be identified: the free YSZ surface, A; the border region with adhering Ni particles, $\mathrm{B}$; and the actual contact area of the Ni electrode, $\mathrm{C}$. The cell had been operated in various gas mixtures and at different anodic and cathodic overpotentials for 135 days. 
Fig. 7. ESEM micrograph of Ni particles adhering to the YSZ surface in the border region of the electrode contact area. This electrode had been operated in $\begin{array}{llll}30 \% & \mathrm{H}_{2} / 3 \% & \mathrm{H}_{2} \mathrm{O} \text { at various }\end{array}$ anodic overpotentials for about 6 days.

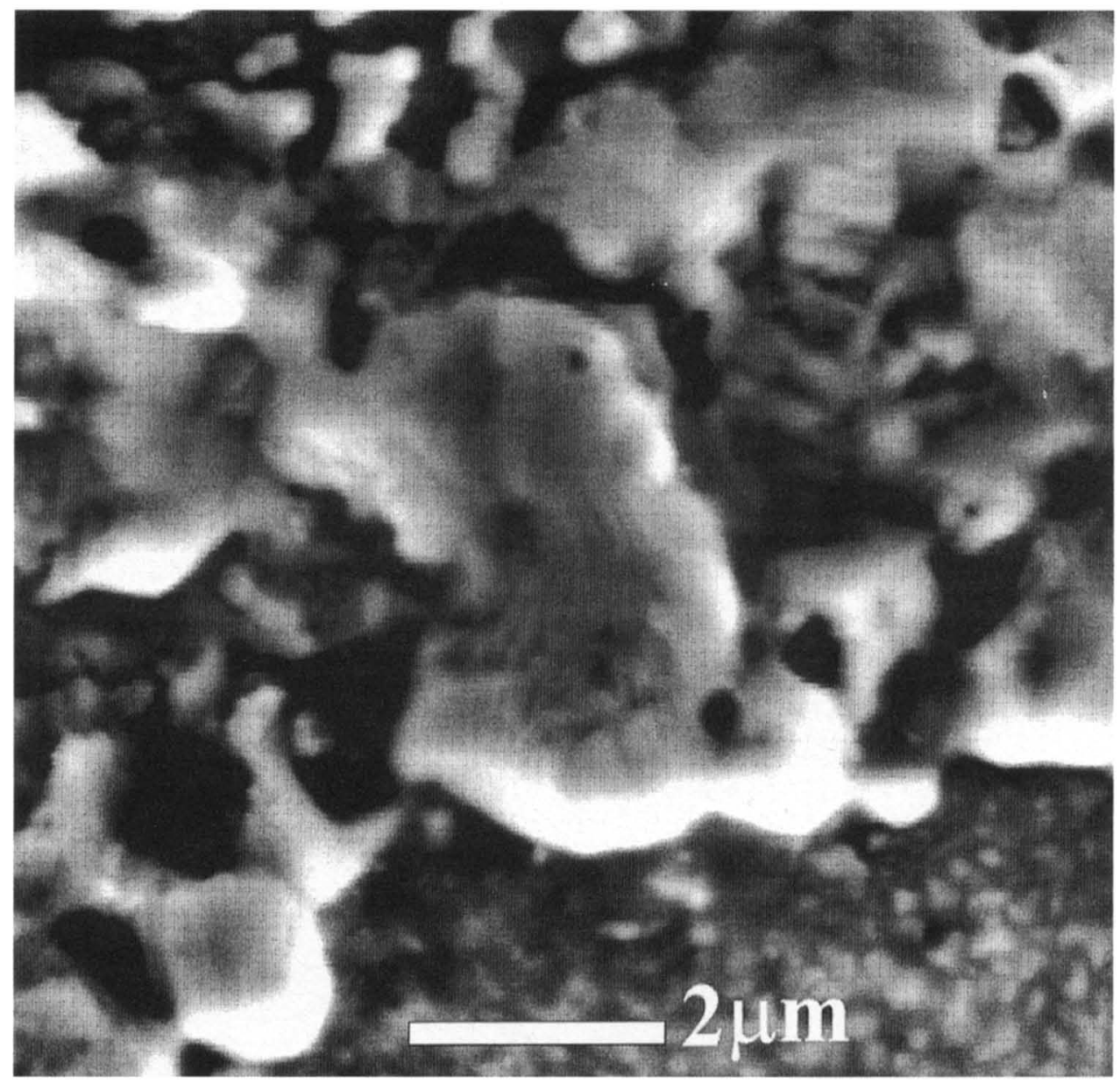

Fig. 8. LVSEM micrograph of a Ni electrode. A fragment of the YSZ electrolyte is adhering to the electrode, identified by marker $A$. The area around marker B shows the bare $\mathrm{Ni}$ metal with some very thin layers of YSZ and impurities accumulated at the interface during operation. This sample had been operated in $30 \% \mathrm{H}_{2} / 3 \%$ $\mathrm{H}_{2} \mathrm{O}$ at various anodic overpotentials for about 13 days.

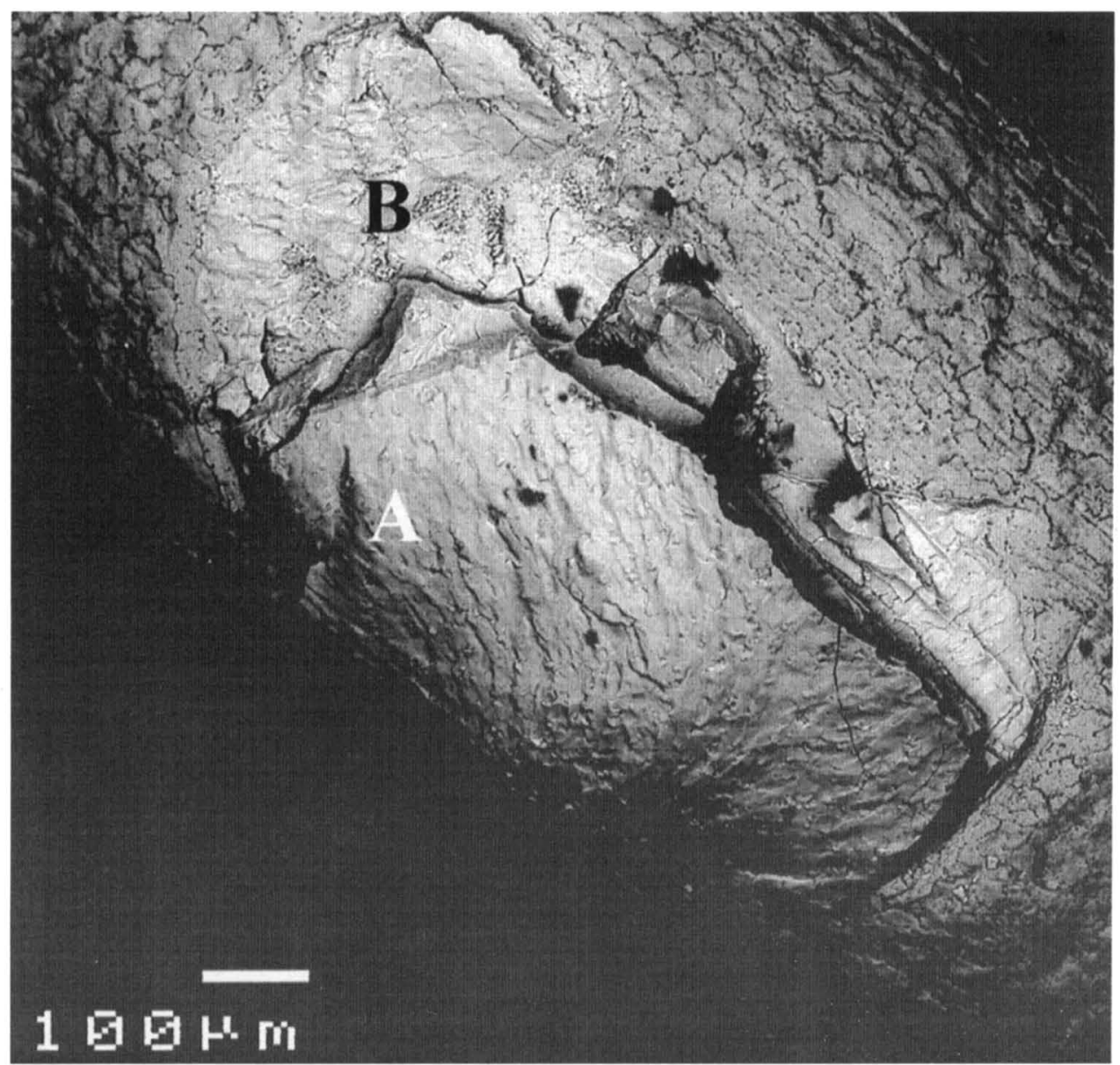




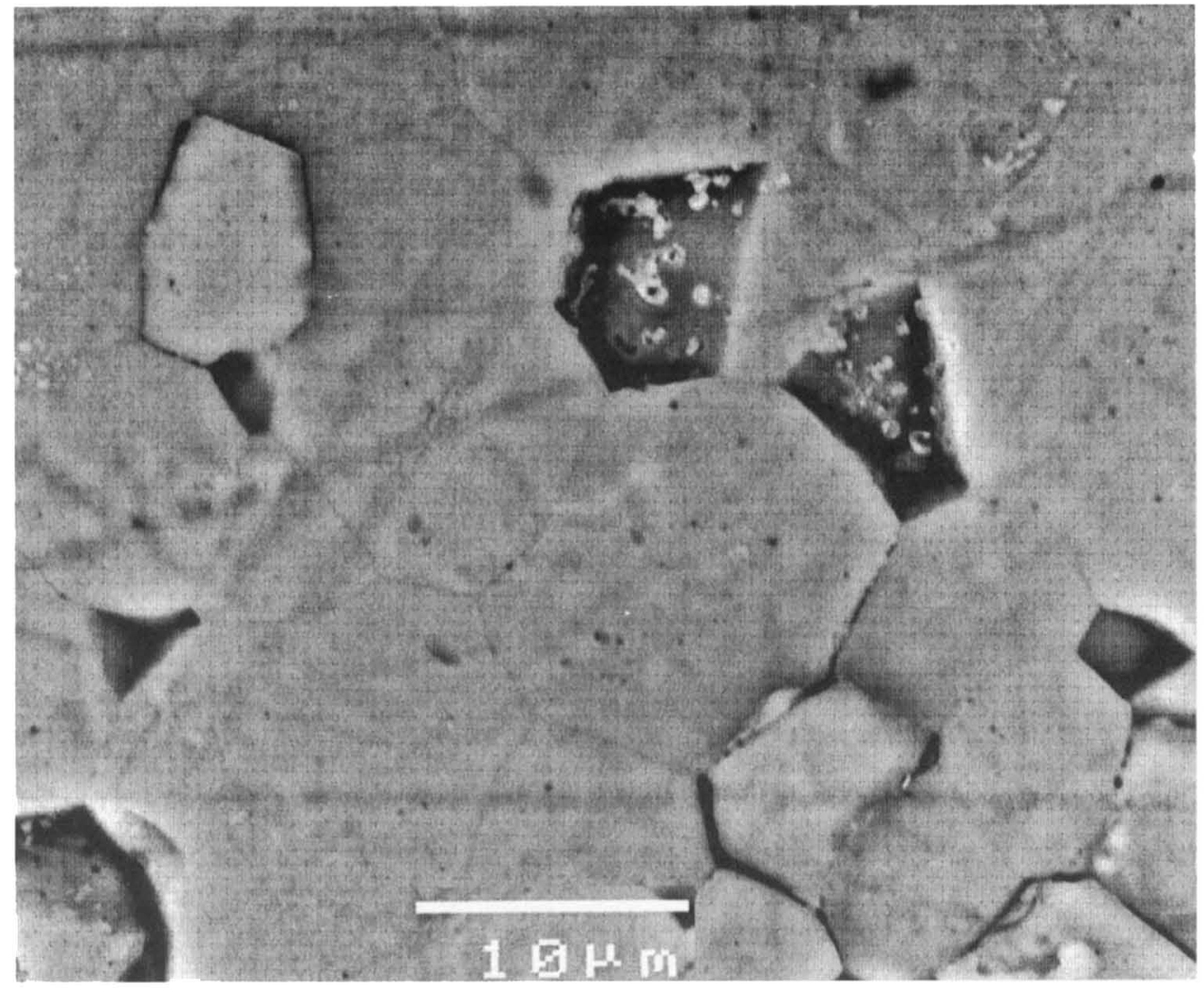

Fig. 9. LVSEM micrograph of the YSZ surface in the electrode contact area. The grain boundaries have been etched during the electrochemical treatment. Some of the grains were ripped out when the electrode was separated from the electrolyte. Scratches from the sample preparation (polishing) are visible. Same sample as in Fig. 7.

cubic YSZ. Peaks at lower wavenumbers are caused by off-center phonons in the cubic phase. The fluorescence bands at 956 and $1020 \mathrm{~cm}^{-1}$ are possibly due to impurities. ${ }^{11}$ Figure 10 is virtually identical to spectra recorded on nonpolarized YSZ and can be regarded as a reference spectrum for the present cubic YSZ samples.

Spectra were obtained from the electrode contact area, from the periphery of the contact area and from the free YSZ surface on all the samples. The bands for cubic zirconia were recorded from all the samples exposed to operating conditions up to 21 days, although the signals were quite weak in some of the spectra. The weaker signals can be accounted for by the shielding effect of metallic Ni particles. As Fig. 11 shows, spectra recorded at very thin residue of YSZ on the Ni surface (marker B in Fig. 8) included several bands in addition to the response from cubic YSZ. The intensity of these new bands varied at different

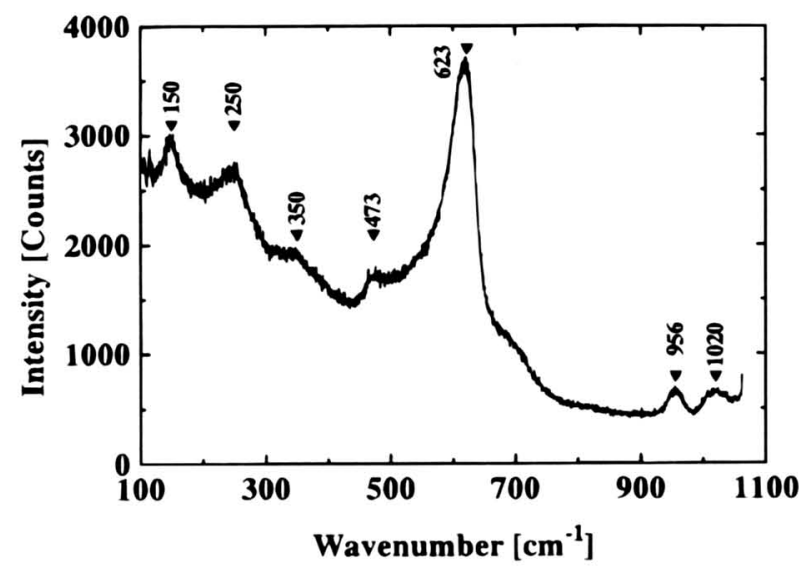

Fig. 10. Raman spectrum of YSZ grains adhering to the Ni electrode (obtained at marker A in Fig. 8). These grains were situated up to $100 \mu \mathrm{m}$ into the bulk electrolyte before they were ripped out when the cell was dismounted. The grains thus represent bulk electrolyte. positions across the surface, indicating that more than one unidentified phase was present at the Ni/YSZ interface.

Raman spectra from the only long time exposed sample (135 days at operating conditions) did not show any indication of cubic zirconia. Instead the bands of this spectrum (Fig. 12) are located at the wavenumbers reported for tetragonal YSZ. ${ }^{11}$ Identical spectra were found all across the electrolyte, both in the electrode contact area and on the free surface. On the contrary, X-ray diffractograms of the same sample had reflections exclusively from cubic YSZ as Fig. 13 shows. Compared to the Raman spectra, the $\mathrm{X}$-ray diffraction pattern is due to the whole bulk of the electrolyte and not just a limited layer on the surface of the electrolyte. The tetragonal YSZ signal in Fig. 12 thus represents only the surface of the electrolyte.

\section{Discussion}

In general, the performance of an electrode is defined by the specific activity of the reaction zone and its geometric extension. Changes in $I$ when the temperature, potential, and partial pressures of $\mathrm{H}_{2}$ and $\mathrm{H}_{2} \mathrm{O}$ are kept constant are

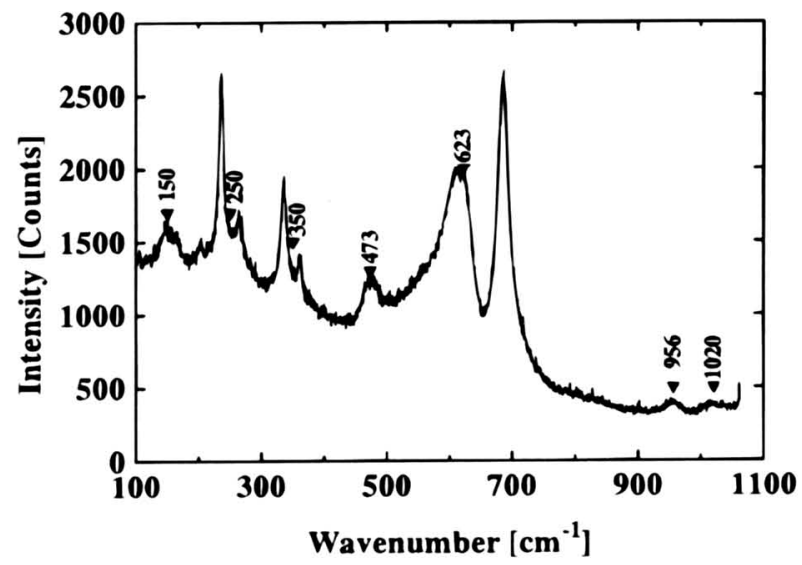

Fig. 11. Raman spectrum of the thin layer of YSZ adhering to the $\mathrm{Ni}$ electrode (obtained at marker B in Fig. 8) 


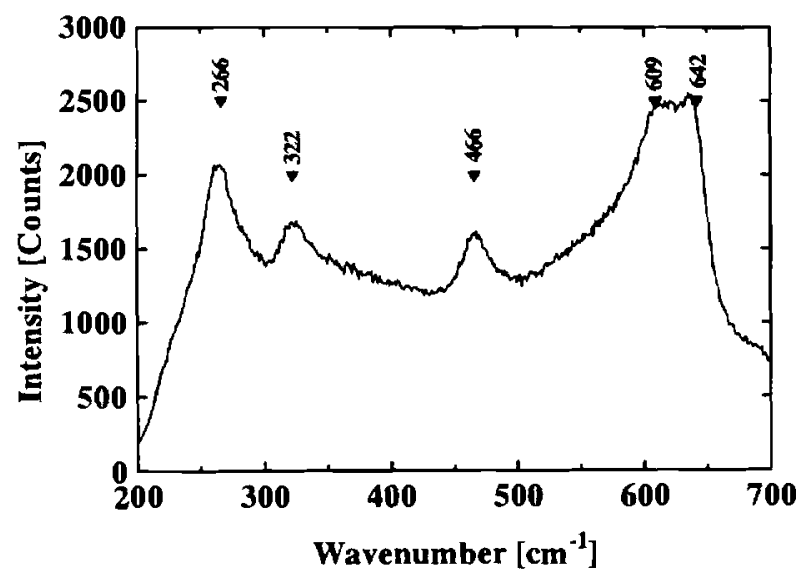

Fig. 12. Raman spectrum of the YSZ surface outside the electrode contact area of the long-term sample. The spectrum was recorded at marker $A$ in Fig. 6 .

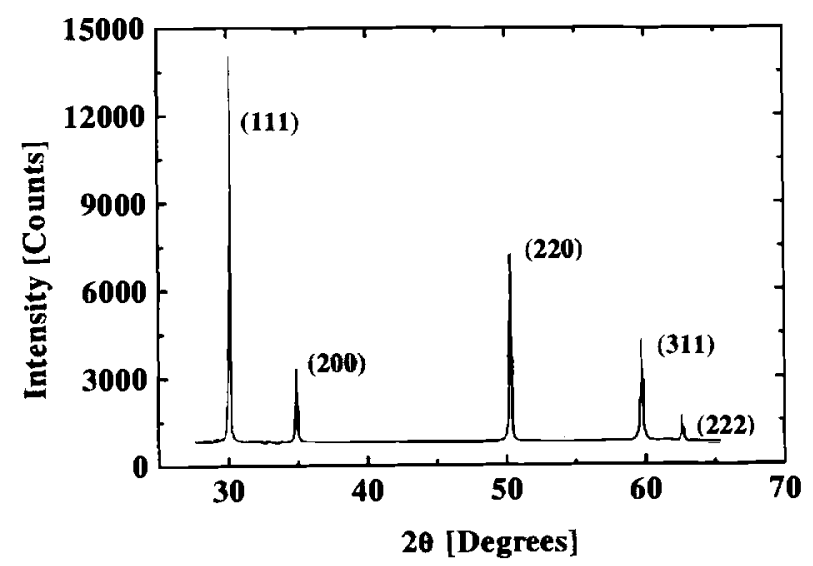

Fig. 13. X-ray diffractogram of the bulk YSZ electrolyte after $135 \mathrm{~h}$ operation (same sample as in Fig. 12). All peaks are identified as due to cubic YSZ of the fluorite structure.

therefore due to variations in one or both of these properties. According to Newman, ${ }^{7} R_{\mathrm{s}}$ depends on the conductivity of the electrolyte at the interface and the radius of contact area. For a circular contact area the formula

$$
R_{\mathrm{s}}=\left(4 \sigma r_{\mathrm{s}}\right)^{-1}
$$

is valid, where $\sigma$ is the specific conductivity of the electrolyte and $r_{s}$ is the radius of the contact. Although in our case the contact area between the $\mathrm{Ni}$ wire and the electrolyte was elliptical, the observed changes in $R_{\mathrm{s}}$ should be due to changes in $\sigma$ and/or the effective $r_{s}$.

It was observed that the long-term anodic activation of the electrode depends on the polarization history over the previous days. Since the deactivation at cathodic potentials was significant only for electrodes that previously had been polarized to anodic overpotentials, one may suggest that the change was dominated by relaxation from an activated state generated during the previous anodic polarization. Taking into account the observation that $\mathrm{Ni}$ particles were created around the electrode at anodic overpotentials and not at cathodic overpotentials, the $\mathrm{H}_{2}-\mathrm{H}_{2} \mathrm{O}$, $\mathrm{Ni} / Y S Z$ anode should be regarded as a dynamic system characterized by redistribution of $\mathrm{Ni}$ on the electrolyte surface. Transport of $\mathrm{Ni}$ from the electrode to the electrolyte surface would create more, or larger, metal grains. If these were in contact with both the $\mathrm{Ni}$ wire and the electrolyte, the effective TPB length would increase compared to the initial electrode contact circumference. Simultaneous agglomeration would reduce the number of Ni particles and counteract the TPB expansion. In the beginning of an anodic potential step, the transfer of $\mathrm{Ni}$ will dominate over the agglomeration, and the reaction zone will increase. An apparent steady state will be established when the two processes counterbalance and the TPB length is constant. The extended reaction zone is anticipated to accommodate higher $I$, and reduce the $R_{\mathrm{s}}$ due to the wider contact area. The experimental observations conform to this idea, although considerable variations in the anodic current from 40 to $140 \mathrm{~h}$ after polarization show that no real steady state is obtained.

Assuming that the transfer of $\mathrm{Ni}$ species to the electrolyte is suppressed at OCV and cathodic overpotentials, the agglomeration processes will dominate over the creation of new particles. The predicted effects would be reduced TBP length, decreasing $I$, and higher $R_{\mathrm{s}}$, as are in fact observed experimentally.

Irrespective of the actual transport mechanism, the results strongly indicate that $\mathrm{Ni}$ species are transferred to the electrolyte by the passage of anodic current. Under the assumption of no temperature gradient, the driving force must be related to gradients in the chemical or electrochemical potentials near the TPB. Very close to the TPB there is a sharp gradient in the $p_{\mathrm{H}_{2} \mathrm{O}} / p_{\mathrm{H}_{2}}$ ratio when current is drawn from the electrode. During anodic polarization, the equivalent $p_{\mathrm{O}_{2}}$ is highest at the TPB, while for cathodic polarization the gradient for increasing $p_{\mathrm{O}}$ is directed outward. Gubner et al. ${ }^{12}$ claim that diffusion of $\mathrm{Ni}(\mathrm{OH})_{2}$ vapor accounts for a significant transportation of $\mathrm{Ni}$ in the $\mathrm{Ni}$ YSSZ cermet electrode, in particular at high oxygen partial pressures where $\mathrm{Ni}(\mathrm{OH})_{2}$ is more stable. We suggest that the same mechanism is taking place on the single contact $\mathrm{H}_{2}-\mathrm{H}_{2} \mathrm{O}, \mathrm{Ni} / \mathrm{YSZ}$ electrode. Thermodynamic calculations using the online $\mathrm{F}^{*} \mathrm{~A}^{*} \mathrm{C}^{*} \mathrm{~T} 2.1$ EQUILIB-Web program $^{13}$ show that a minimum of $1 \mu \mathrm{m}^{3} \mathrm{Ni}_{(\mathrm{s})}$ may leave the reaction zone per hour. This result is based on a gas exchange equal to the $\mathrm{H}_{2}$-consumption at the electrode when $I=300 \mu \mathrm{A}$. A gas mixture equivalent to $p_{\mathrm{H}_{2} \mathrm{O}} / p_{\mathrm{H}_{2}}=$ 10 was chosen to simulate the equilibrium ratio at $-750 \mathrm{mV}$ vs. the air, Pt/YSZ electrode. All chemical reactions were assumed to be at equilibrium. The estimated Ni transport is one or two orders of magnitude too small to account for the amount of metal found as particles on the electrolyte. However, the agitation caused by gas flow through the furnace will cause a considerably higher gas exchange and Ni transport from the electrode. Because the $p_{\mathrm{H}_{2} \mathrm{O}} / p_{\mathrm{H}_{2}}$ ratio quickly decreases away from the TPB, most of the Ni precipitates as metal near the electrode/electrolyte contact, and a substantial amount of Ni accumulates in this area

Alternatively, Ni ions may be transferred electrochemically from the electrode to the electrolyte by an underpotential deposition mechanism. The ions are then reduced to neutral $\mathrm{Ni}$ when leaving the anodic reaction zone. Although bulk thermodynamics are not in favor of this mechanism, $\mathrm{NiO}$ is suggested to exist on the metal surface even in reducing atmospheres. ${ }^{14}$ Since a small amount of $\mathrm{NiO}$ is soluble in YSZ, ${ }^{15}$ it may be possible that $\mathrm{Ni}$ species interact with the electrolyte and are transferred by surface or subsurface diffusion from the Ni/YSZ interface. None of the above hypotheses has been evaluated experimentally, but all the suggested mechanisms support the fact that the transfer of $\mathrm{Ni}$ increases with increasing anodic overpotential. Due to the high surface mobility of $\mathrm{Ni}$ at the present temperature, ${ }^{16}$ spillover of $\mathrm{Ni}$ atoms to the electrolyte may be an additional $\mathrm{Ni}$ redistribution mechanism. However, this process would not depend on the direction of the electrode current and is therefore probably of little significance.

As seen in Fig. 2 to 3 , I reaches steady state faster than $R_{\mathrm{s}}$; consequently more than one process must be contributing to the variations in the electrode activity and $R_{\mathrm{s}}$. Etching of the electrolyte grain boundaries and transport of YSZ species may have contributed to the morphological changes, although this would not give rise to deviating time constants. Changes in the catalytic activity of the materials or the electrolyte conductivity must have taken 
place simultaneously with the material redistribution. A change in the properties of the electrode or the electrolyte surfaces can also rationalize the gradual change from a positive to a negative inductance as $I$ increased toward steady state at high anodic overpotentials. Compared to the results of Bay and Jacobsen, ${ }^{5}$ the anodic activation of the $\mathrm{H}_{2}, \mathrm{H}_{2} \mathrm{O}, \mathrm{Ni} / \mathrm{YSZ}$ electrode is much stronger than for the $\mathrm{O}_{2}, \mathrm{Pt} / \mathrm{YSZ}$ electrode. At cathodic potentials the $\mathrm{O}_{2}$, $\mathrm{Pt} / \mathrm{YSZ}$ electrode was activated, contrary to what was observed for the $\mathrm{H}_{2}, \mathrm{H}_{2} \mathrm{O}, \mathrm{Ni} / \mathrm{YSZ}$ electrode in the present investigation. In addition are the time constants longer than those observed for our electrode. Knowing that Ni species have several orders of magnitude higher partial pressures in $\mathrm{H}_{2}-\mathrm{H}_{2} \mathrm{O}$ mixtures than $\mathrm{Pt}$ species have in $\mathrm{O}_{2}$ atmospheres, we believe that the dominating activation/deactivation mechanism in the $\mathrm{H}_{2}, \mathrm{H}_{2} \mathrm{O}, \mathrm{Ni} / \mathrm{YSZ}$ electrode is the morphological changes due to redistribution of $\mathrm{Ni}$.

The time constants found by long-term potential-step measurements are about four orders of magnitude larger than for the low-frequency response of the ac impedance. The processes accounting for variations in material properties and morphology cannot be directly reflected in the impedance spectra. A theoretical model which involves two or more adsorbed species, was able to account for the low-frequency inductive tail of the impedance spectra ${ }^{17,18}$ Because the model allows negative inductive elements, it also describes roughly the low-frequency tail when it curves back into the capacative quadrant of the spectrum, as in Fig. 5c. A thorough discussion of this model will be presented elsewhere. ${ }^{19}$ Other explanations for the inductive low-frequency impedance signal that were mentioned in the introduction do not comply with our results. An extension of the reaction zone due to electronic conductivity in the electrolyte subsurface or changes in the TPB length ${ }^{5}$ cannot account for a transition to negative inductance at increasing anodic overpotentials (Fig. 5c). Guindet et al ${ }^{20}$ suggested that a negative inductive tail was due to passivation of the $\mathrm{Ni}$ electrode at high potentials, but when comparing Fig. $5 \mathrm{~b}$ and $\mathrm{c}$ this cannot be the case. It is unlikely that the electrode (in Fig. 5c) was more prone to oxidation in a more reducing atmosphere and at a lower absolute electrode potential. The negative inductive loop is therefore related to the overpotential, not to the absolute potential, and is probably a result of the faradaic processes as described by the theoretical impedance model. ${ }^{19}$

Ex situ Raman spectroscopy did not reveal any permanent phase change near the electrode contact point. The tetragonal phase covering the surface of the long-time exposed sample is most likely due to aging of the sample and not the electrochemical processes at the electrode. ${ }^{21}$ The opaque character of the YSZ grains reduced the surface sensitivity of the Raman spectra. Combined with the rather coarse lateral resolution, signals from any secondary surface structure may not be sufficiently strong to be detected. Any current-induced reorganization of the interface structure cannot conclusively be excluded by these experiments.

The impurity elements identified with EDX analysis at the Ni/YSZ interface may be contained in the unidentified phases resolved by Raman spectroscopy in the same area. It is, of course, possible that these contaminations interact with the electrolyte surface and modify the specific catalytic activity of the electrode and $R_{\mathrm{s}}$ through $\sigma$. Nevertheless, this does not alter the conclusions regarding the effect of material transport which is considered as the primary mechanism for activation and deactivation of the electrode.

\section{Conclusions}

Long-term potential-step measurements have shown that the $\mathrm{H}_{2}-\mathrm{H}_{2} \mathrm{O}$, Ni/YSZ point electrode induces a selfcatalytic effect at anodic overpotentials. At cathodic overpotentials, the electrode activity is constant or reduced with time. $\mathrm{Ni}$ particles are growing at the YSZ surface during anodic polarization, resulting in an extension of the TPB length and increasing electrode activity. At cathodic overpotentials, new Ni particles are not created, but if they are present from previous anodic polarization, they tend to agglomerate. Further variations in the electrode activity are caused by slow changes in the area specific catalytic properties of the surfaces. The results show that the low-frequency response in the impedance spectra is dominated by faradaic relaxation processes rather than structural or morphological variations.

Phase transformations were observed on the long-term electrolyte sample, but these are attributed to segregation of the YSZ. The passage of current was not found to generate any permanent phase transformation in the YSZ.

\section{Acknowledgments}

This work was financially supported by the Nordic Energy Research Program. Laboratory facilities were provided by Statoil Forskningssenter (Norway) and Forskningscenter Risø (Denmark). M. Nissum and P. W. Jensen at Odense University (Denmark) kindly recorded the Raman spectra. C. C. Appel (Risø), T. Boassen, and B. Schmid (Statoil) assisted in LVSEM, ESEM, and EDX analyses. T. Tharaldsen at the Norwegian University of Science and Technology performed the X-ray diffractometry. The Raman spectrometer at the Technical University of Denmark was purchased with funds received from Thomas B. Thriges Fond, Danfoss A/S, and the Danish Technical Research Foundation.

Manuscript submitted December 2, 1997; revised manuscript received March 11, 1998.

Statoil Forskningssenter assisted in meeting the publication costs of this article.

\section{REFERENCES}

1. M. Mogensen, S. Sunde, and S. Primdahl, in High Temperature Electrochemistry: Ceramics and Metals, Proceedings of 17th Risø International Symposium on Materials Science, F. W. Poulsen, N. Bonanos, S. Linderoth, M. Mogensen, and B. Zachau-Christiansen, Editors, p. 77, Roskilde (1996).

2. S. Pizzini, M. Bianchi, P. Colombo, and S. Torchio, $J$. Appl. Electrochem., 3, 153 (1973).

3. E. J. L. Schouler and M. Kleitz, J. Electrochem. Soc., 134, 1045 (1987).

4. T. Jacobsen, B. Zachau-Christiansen, L. Bay, and S Skaarup, in High Temperature Electrochemistry: Ceramics and Metals, Proceedings of 17 th Rise International Symposium on Materials Science, F. W. Poulsen, N. Bonanos, S. Linderoth, M. Mogensen, and B. Zachau-Christiansen, Editors, p. 29, Roskilde (1996).

5. L. Bay and T. Jacobsen, Solid State Ionics, 93, 201 (1997).

6. M. Mogensen, S. Primdahl, J. T. Reinländer, S. Gormsen, S. Linderoth, and M. Brown, in Solid Oxide Fuel Cells IV, M. Dokiya, O. Yamamoto, H. Tagawa, and S. C. Singhal, Editors, PV 95-1, p. 657, The Electrochemical Society Proceedings Series, Pennington, NJ (1995).

7. J. Newman, J. Electrochem. Soc., 113, 501 (1966).

8. R. J. Aaberg, R. Tunold, and R. Ødegård, Paper to be presented at 3rd European Solid Oxide Fuel Cell Forum, Nantes (1998).

9. B. A. Boukamp, Equivalent Circuit, Internal Report CT89/214/128, University of Twente, (1989).

10. C.-D. Qin and B. Derby, J. Mater. Res., 7, 1480 (1992).

11. N. Kjerulf-Jensen, R. W. Berg, and F. W. Poulsen, in Proceedings of 2 nd European Solid Oxide Fuel Cell Forum, B. Thorstensen, Editor, p. 647, Oslo (1996).

12. A. Gubner, H. Landes, J. Metzger, H. Seeg, and R Strüber, in Solid Oxide Fuel Cells $V$, M. Dokiya, $O$. Yamamoto, H. Tagawa, and S. C. Singhal, Editors, PV 97-40, p. 844, The Electrochemical Society Proceedings Series, Pennington, NJ (1997).

13. $\mathrm{F}^{*} \mathrm{~A}^{*} \mathrm{C}^{*} \mathrm{~T} 2.1$ EQUILIB-Web, at http://www.cret. polymtl.ca/fact/web/equiweb.htm, update 15 , September 1997, Center for Research in Computational Thermochemistry, École Polytechnique de Montréal, Montréal (1997).

14. S. P. Jiang and S. P. S. Badwal, J. Electrochem. Soc. 144, 3777 (1997).

15. A. Kuzjukevics and S. Linderoth, Solid State Ionic, $\mathbf{9 3}$, 255 (1997) 
16. S. Skaarup, B. Zachau-Christiansen, and T. Jacobsen, in High Temperature Electrochemistry: Ceramics and Metals, Proceedings of 17th Risø International Symposium on Materials Science, F. W. Poulsen, N Bonanos, S. Linderoth, M. Mogensen, and B Zachau-Christiansen, Editors, p. 423, Roskilde (1996).

17. B. A. van Hassel, B. A. Boukamp, and A. J. Burggraaf, Solid State Ionics, 48, 139 (1991).

18. G. Ø. Lauvstad, Ph.D. Thesis, Norwegian University of
Science and Technology, Trondheim (1996)

19. R. J. Aaberg, In preparation

20. J. Guindet, C. Roux, and A. Hammou, in Proceedings of 2nd International Symposium on SOFCs, F. Gross, P. Zegers, S. C. Singhal, and O. Yamamoto, Editors, p. 553, Athens (1991)

21. J. Nowotny, in The CRC Handbook of Solid State Elec trochemistry, P. J. Gellings and $\mathrm{H}$. J. M. Bouwmeester, Editors, p. 121, CRC Press, Boca Raton, FL (1997).

\title{
On the Reduction of Lithium Insertion Capacity in Hard-Carbon Anode Materials with Increasing Heat-Treatment Temperature
}

\author{
Edward Buiel, A. E. George, and J. R. Dahn* \\ Department of Physics, Dalhousie University, Halifax, Nova Scotia, Canada, B3H $3 J 5$
}

ABSTRACT

"Non-graphitizable" or "hard" carbon anode materials have almost twice the capacity (per unit mass) of graphitic materials that currently represent the industrial standard for Li-ion batteries. One problem with hard carbon is the small hysteresis in the voltage profile between charge and discharge. This small hysteresis has been correlated to residual hydrogen content after pyrolysis $(<0.5 \%$ by mass) and can almost be eliminated by increasing the heat-treatment temperature (HTT) above $1100^{\circ} \mathrm{C}$. However at this temperature hard carbon begins to show a reduction in reversible capacity. This capacity reduction is correlated to a shift in chemical potential of lithium inserted into the hard-carbon structure and to the closure of micropores in the sample. Hard carbons were prepared by pyrolysis of sucrose between HTTs of 900 and $1400^{\circ} \mathrm{C}$. The structure of these materials was determined by wide angle X-ray scattering (WAXS) and small-angle X-ray scattering (SAXS). WAXS results show that the number of stacked layers increases with HTT, and SAXS measurements show that the micropore size also increases with HTT. $\mathrm{N}_{2}$ Brunauer-Emmett-Teller (BET) surface area and CO urements show that the mich show a dramatic decrease in surface area and open micropore volume for HTTs greater than $1100^{\circ} \mathrm{C}$. These results indicate that the micropores in the samples begin to close and produce what we call "embedded fullerenes." Based on recent results of intercalation in $\mathrm{C}_{60}$, we believe that embedded fullerenes are impenetrable by lithifullerenes." Based on recent results of intercalation in $\mathrm{C}_{60,}$, we believe that emberes. This, we propose, is the mechanism for the observed capacity loss in hard carbon at HTTs greater than $1100^{\circ} \mathrm{C}$.

\section{Introduction}

Hard-carbon anode materials with large reversible capacity have been reported by numerous authors. ${ }^{1-5}$ In Fig. 1, a typical hard-carbon voltage profile is compared to that of a graphitic material that typifies the negative electrode (anode) materials found in commercial Li-ion batteries. Hard carbons have two major deficiencies: the large irreversible capacity and the hysteresis between charge and discharge in the voltage profile. We have recently shown ${ }^{6}$ that the irreversible capacity in hard carbon can be reduced to $50 \mathrm{mAh} / \mathrm{g}$ through the chemical vapor deposition (CVD) of a carbonaceous material on the surface of the carbon from ethylene gas. Hence, reducing the hysteresis in the voltage profile is critical for optimizing the performance of hard carbon in practical Li-ion cells.

The hysteresis in the voltage profile has been correlated to the residual hydrogen content in hard carbons that decreases with increased HTT., ${ }^{3,8}$ In order to reduce the hysteresis one would simply increase the HTT and drive off more hydrogen from the sample in the form of $\mathrm{H}_{2}$ or $\mathrm{CH}_{4}$ gas. However, before the hysteresis is eliminated, the lithium insertion capacity begins to decrease above a critical temperature. Understanding why this reduction in capacity occurs is the goal of this paper.

We have prepared a series of samples from sucrose pyrolyzed at temperatures between 900 and $1400^{\circ} \mathrm{C}$. Electrochemical methods were used to measure the differential capacity of the samples as a function of voltage. X-ray diffraction, $\mathrm{SAXS}$, and $\mathrm{CO}_{2}$ gas adsorption measurements were used to characterize the stacking of graphene sheets, the number and size of micropores and the open microporosity of the samples. We show that the lithium insertion

* Electrochemical Society Active Member capacity associated with the filling of the micropores is eliminated as the HTT increases. This occurs for two reasons. First, the micropores close as the HTT increases, thereby preventing $\mathrm{Li}$ insertion. Second, the chemical potential of the $\mathrm{Li}$ inserted in the micropores increases to nearly that

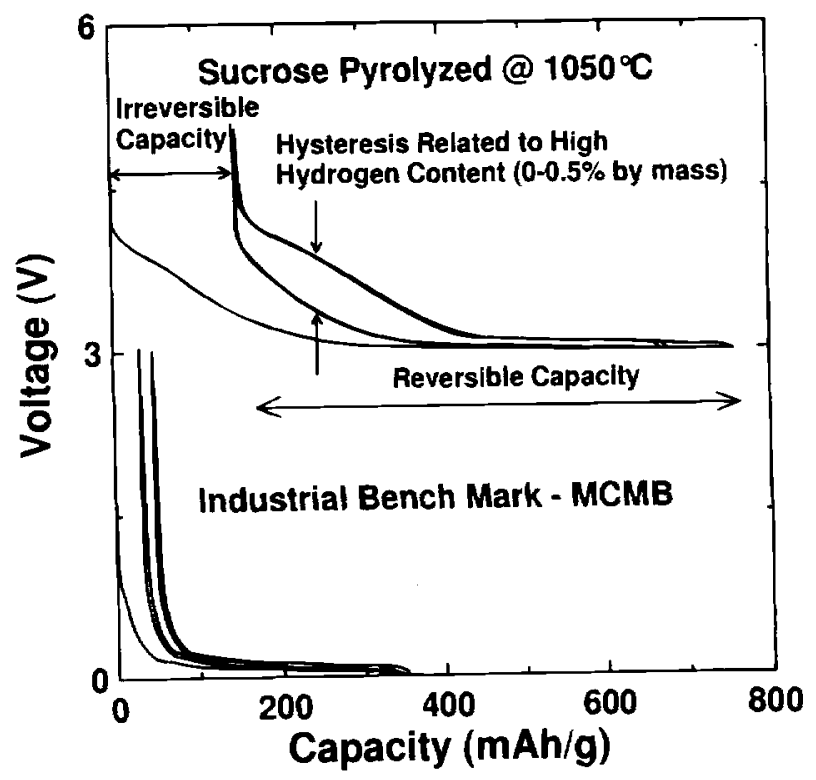

Fig. 1. The voltage profiles of a typical hard carbon anode material and $M C M B$, a graphitic material. The hard carbon voltage curve has been shifted by $3 \vee$ for clarity. 